\title{
Fruit Defects in Basswood (Tilia americana L.)
}

\author{
By GEORGE STROEMPL \\ Ontario Department Lands \\ and Forests, \\ Southeastern Research Unit, \\ Tweed, Ont. \\ ODC 416.2
}

Damage to the pericarp or woody husk of basswood fruit (Tilia americana L.) has been reported from field collections in the Tweed Forest District, southeastern Ontario (Stroempl, 1968). This note now describes various fruit blemishes and determines their relationship to seed quality.

An examination of two 25-fruit samples from each of ten trees in September, and equal samples in October, 1967 showed the following classes and prevalence of blemishes:

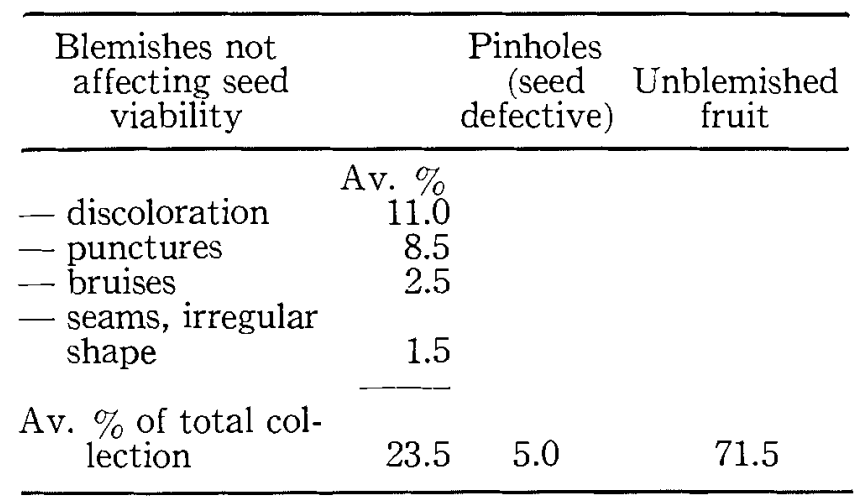

Blemishes of the pericarp are illustrated in Figure 1. Discoloration (A), punctures (B) and discolor- ation extending in to the endocarp (C) did not affect seed quality. Pinholes (D) were either in the periphery of the pericarp, or one hole was at the onset of the fruit stalk indicating the presence of defective seed in every fruit. There were $3 \%$ holes recognized in fruit of the September collection as compared to $7 \%$ of the October collection.

Figure 2 shows the late instar, possibly last-instar, larva about $7.5 \mathrm{~mm}$ long and described by Mackay (1959) as Phalonia straminoides Grt. Figure 3 shows borings in twin seeds. Prentice (1965) compiled some survey records of this seed feeder on basswood.

In general the soundness of a collection can be assessed as the percentage of the fruit free of pinholes. Occasionally however, trees may produce fruit without seed (parthenocarpy) and it is a wise precaution to examine a sample for this defect, to exclude unsuitable trees.

\section{Acknowledgement}

The author wishes to thank M. R. Mackay of the Entomology Research Institute, Canada Department of Agriculture, Ottawa for identifying the species.

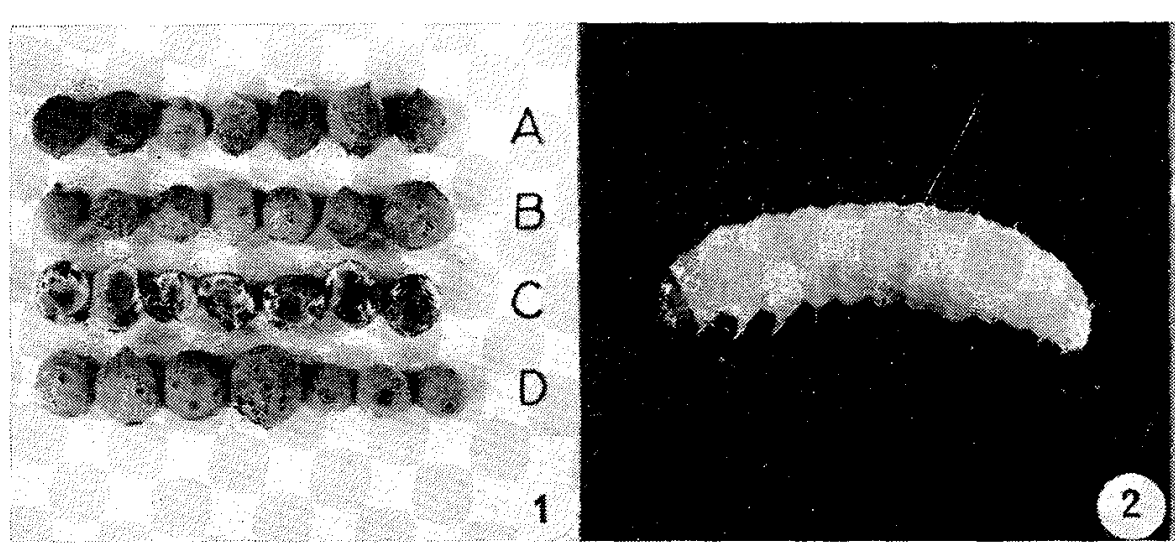

Fig. 1. Blemishes of basswood fruit, Tilia americana $L$. A discoloration; B - multiple fine punctures; $C-$ dissected fruit showing discolorotion extending to endocarp; $D$ - pin hole borings by the larvoe of Phalonia straminoides. Fig. 2.

\section{References}

MACKAY, M. R. 1959. Larvae of the North American Olethreutidae (Lepidoptera). Mem. Ent. Soc. Can. No. 10 p. 14. PRENTICE, R. M. (compiler) 1965. Forest Lepidoptera of
Late instar lorva of $\mathbf{P}$. straminoides removed from basswood fruit. Fig. 3. Borings by $P$. straminoides in twin seeds of basswood.
Canada, Vol. 4, Microlepidoptera. Can. Dept. For. Publ. 1142: p. 739.

STROEMPL, G. 1968. Relationships of fruit and seed form, size, weight and soundness of graded basswood fruit. Tree Planters' Notes, 19 (2): 22-28. 